\title{
Mostra Nacional de Saúde da Família Os Desafios após 10 anos
}

\author{
Eno Dias de Castro Filho \\ Médico de Família e Comunidade \\ Mestre em Educação \\ Diretor Científico da SBMFC \\ Gerente da Saúde Comunitária do Grupo Hospitalar Conceição/MS
}

\section{Resumo}

A II Mostra Nacional de Saúde da Família apresentou a face da Atenção Primária à Saúde no SUS. A SBMFC esteve na mesa de abertura, na apresentação e coordenação dos trabalhos. Educação permanente, avaliação, financiamento, resolutividade, eqüidade, suporte, equipe, controle social e protocolos dominaram o temário. Partindo de uma inorganicidade de rede, o país decidiu tecê-la a partir da APS. Porém, o PSF concretizou apenas parcialmente a motivação inicial. Avançou paralelo ao restante do SUS, e precarizado. Os movimentos sociais pressionam por medidas que aproximem o SUS das promessas constitucionais. Assumindo no MS uma equipe oriunda da Reforma Sanitária, abriu-se caminho para a mudança. Várias iniciativas confluem para avançar. A mudança requer definir melhor os contornos do modelo tecno-assistencial: assumir o MFC como a opção para a porta de entrada do SUS, criar diretrizes para Plano de Carreira do SUS, financiar o apoio matricial à APS são medidas igualmente necessárias.

\section{Abstract}

The II National Sample of Family Health has presented the face of the Primary Health Care (PHC) in the SUS. The SBMFC was as in the opening table, as in the presentation and coordination of the works. Permanent education, evaluation, financing, resolutividade, fairness, support, team, social control and protocols have dominated the agenda. Starting from a net's inorganicity, Brazil decided to weave it from the PHC. However, the PSF have only partially materialized the initial motivation. It has advanced in parallel with the remain of the SUS, but precarizado. The social movements have been pressing for measures able to approach the SUS to the Constitution's promises. Assuming the MS a team derived from the Sanitary Reformation, a way for the change has been opened. Many initiatives are joining to advance. Change requires a better definition of the tecnoassistence model's outlines: the assumption of the MFC as the choice for the entrance door of the SUS, the creation of direction lines for a SUS' Career Plan and financing the matricial support to the PHC are also necessary measures. 


\section{Descritores}

SAUDE DAFAMILIA, AVALIAÇÃO DE PROGRAMAS, SUS

\section{Introdução}

Nos dias 1 a 3 de junho de 2004, a capital federal viu um pouco do que o SUS tem de melhor para apresentar em seus quase 16 anos de existência. Cerca de 3500 pessoas foram à II Mostra Nacional de Saúde da Família exibir a nova cara da Atenção Primária à Saúde no Brasil. Nossa Presidente da SBMFC, Dr ${ }^{\mathrm{a}}$ Maria Inez Padula Anderson, estava presente na mesa de abertura do evento, em nítido reconhecimento da importância da especialidade para o Ministério da Saúde atual. Além dela, vários integrantes de nossa Diretoria, além de outros sócios, colaboraram na coordenação de mesas e painéis. E também expuseram trabalhos exemplares.

Médicos da atenção primária, agentes comunitários de saúde e, virtualmente, todas as profíssões da área debateram, durante 3 dias os avanços da Saúde da Família e seus gargalos. A equipe dirigente do MS participou em peso.

Educação permanente, avaliação, financiamento, resolutividade, eqüidade, suporte, trabalho em equipe, controle social e protocolos dominaram o temário. O evento não foi voltado a gerar conclusões ou recomendações. Priorizou intercâmbio, socialização e integração. No entanto, cumpre que reflitamos sobre os desafios colocados.

\section{O ponto de partida}

O Brasil não é uma pequena nação. É uma grande federação que, corretamente, decidiu trilhar os caminhos da descentralização da Saúde com a Constituição de 1988 (art.198). Partindo de uma situação de completa inorganicidade de rede, salvo experiências localizadas, o país decidiu tecê-la a partir da Atenção Primária à Saúde(APS). Brotava o PSF, 6 anos depois da criação do SUS. Em sua concepção inicial, tiveram fundamental contribuição os profisssionais da então Medicina Geral Comunitária (hoje MFC), notadamente os da Saúde Comunitária do GHC, em 1993. No entanto, o PSF só concretizou parcialmente aquela inspiração inicial. Avançou, em grande parte da nação, como algo paralelo ao restante do SUS, além de precarizado. O conjunto da rede básica préexistente não se modificou. A rede de referência permaneceu autônoma e desvinculada. Tampouco foi viabilizado o acesso a recursos diagnósticos e terapêuticos que deveriam estar disponíveis. Os caminhos para indução de uma autêntica reforma de toda a rede seguiram bloqueados por muito tempo. O padrão de financiamento por procedimento seguiu estimulando a abordagem da doença, não o cuidado de pessoas. A produção de saúde ou de uma nova subjetividade centrada no cuidado só surgiu onde determinantes locais tinham força para tal. A diversidade e autonomia dos municípios, além do desfinanciamento da saúde pública em governos neoliberais, serviram como biombo para a não definição de um modelo geral que norteasse a organização do conjunto do sistema. A contradição entre os princípios constitucionais de Saúde como direito versus a livre exploração empresarial da doença (art.196 e 199) deu guarida geral ao excessivo gasto que o país tem com os sistemas suplementares. E ampliou a dificuldade para a regulação pública de um modelo contra-hegemônico potente. 


\section{Um nó a desatar}

A maior parte dos países que tiveram êxito na constituição de sistemas nacionais de saúde democráticos contaram com um fator decisivo: uma ruptura no rumo político. Foi assim, por exemplo, com a ascensão do velho trabalhismo inglês em meados do século passado (Aneurin Bevan criou o NHS em 1945) e com os revolucionários cubanos e a queda do ditador Batista na década de 50. A concentração de legitimidade que vem de uma grande mudança política permitiu quebrar egoísmos corporativos, contrariar poderosos interesses privados, inverter prioridades e inovar cientificamente. Em pouco tempo, e com apoio da OMS, a Medicina de Família e Comunidade tornou-se a especialidade médica integral sobre a qual se apóia, na porta de entrada principal, todo o sistema de saúde daquelas nações. Foram rapidamente obtidas, no mínimo, melhor relação custo-benefício, igual ou superior resolutividade e maior humanização do que nos sistemas baseados em especialidades focais. Demonstrada a superioridade deste tipo de reorganização, outros países também iniciaram mudanças no mesmo sentido. Mesmo sem rupturas maiores, tais transformações sempre exigiram medidas de força política.

No PSF brasileiro, ao contrário, a adesão dos médicos ainda é devida, em grande proporção, apenas a salários vantajosos com o "paraefeito" de vínculos precários. A maioria não fica 6 meses no mesmo território. O país não está dotado de uma política consistente de formação massiva, plano de carreira, incentivo à pesquisa e atualização do MFC. Os currículos ainda estão presos ao modelo hospitalocêntrico. Mesmo que a graduação não possa formar o especialista em MFC, seus currículos ainda carecem da inclusão teórico-prática das bases da MFC e da APS. A definição de vagas da Residência Médica ainda está submetida a interesses dispersos nos Hospitais de Ensino. Isto obstaculiza a solução de estrangulamentos da referência e contra-referência, além de achatar a resolutividade. É certo: não se poderia esperar as condições ideais para dar início à organização do SUS em rede a partir da APS. Mas também é certo que, em 15 anos, o Estado brasileiro já poderia ter dado grandes passos para ordenar seu crescimento. O nó está exposto: sem decisão política consistente e pesado investimento em formação, valorização, suporte e comunicação, a realidade não muda.

\section{Nó Górdio pode ser rompido?}

Há muitos anos, os movimentos sociais vêm propondo e pressionando pela adoção de um conjunto coerente de medidas que aproxime o SUS das promessas constitucionais. A nomeação, para a direção do Ministério da Saúde, de uma experiente equipe dirigente dos movimentos pela Reforma Sanitária, acendeu a expectativa da concentração de legitimidade e poder requeridas para a mudança. Em que pesem as restrições orçamentárias impostas pela mantida política econômica, várias iniciativas podem confluir para um novo modelo. Algumas vêm amadurecendo há mais tempo, em função das pressões mencionadas. Outras são iniciativas deste governo. 
O PROMED vem incentivar a mudança dos currículos de medicina, operando, entre outras mudanças, a integração entre os chamados ciclos básico e clínico e a inserção precoce dos alunos na APS. Tem, como parâmetros, os princípios do SUS para o cuidado com a pessoa.

Os Pólos de Educação Permanente do SUS vêm para democratizar o acesso a recursos de capacitação, com uma nova filosofia de integração dos sujeitos e de educação permanente. É o leito que também impulsiona a mudança curricular e a pós-graduação em serviço para as demais profíssões da saúde.

O PROESF carrea vultosos recursos de empréstimo internacional para a expansão da Estratégia de Saúde da Família nos grandes centros urbanos. Tem em vista não só aumento de cobertura, mas a recuperação física da rede e a conversão de todo o modelo da chamada atenção básica sob a mesma Estratégia. Ao lado disso, há projetos para enfrentar a geração maciça de brasileiros desdentados, para humanização dos hospitais...

Ainda assim, o nó é muito forte, e resiste a ser desatado à mão. Há elementos necessários para impactar a resolutividade do sistema, para romper gargalos, que requerem outras posturas. Por exemplo, disponibilidade de Serviços de Apoio Diagnóstico e Terapêutico (SADT) à APS, capacitação dos especialistas focais para dar alta a seus pacientes de volta para a APS (possibilitando-lhes absorver novos casos), a informatização das redes, o ordenamento das vagas de residência de acordo com as necessidades do país.

Tudo isso requer uma disposição para definir melhor, em termos nacionais e em parceira com o CONASEMS e CONASS, os contornos indutores do modelo tecnoassistencial no interior do qual os estados e municípios exerceriam sua autonomia. Bem mais do que desembasadas campanhas verticais anteriores, como a de screening em massa para diabetes, esta iniciativa central do governo da União será necessária para passarmos o nó Górdio ao fio da espada.

Concretizando mais a definição: absorção da constatação de que o MFC é a melhor opção para a principal porta de entrada do SUS; determinação aos Hospitais de Ensino para criarem ou adotarem serviços/redes de APS, com investimento maciço na criação de Programas e vagas de Residência Médica na área (preferencialmente em ambiente multiprofissional); apoio à conversão das especializações em residências reconhecidas; formação rápida de um contingente suficiente e crescente de preceptores da especialidade; financiamento crescente ao apoio matricial de especialidades (pediatria, GO, Medicina Interna e outras) e profissões (Nutrição, Psicologia, Serviço Social, Veterinária, Educação Física, Farmácia, as da saúde bucal) junto ao MFC e à enfermagem na porta de entrada principal; fortalecimento da APS na agenda nacional de pesquisa; criação de mestrados e doutorados em APS e MFC; criação das Diretrizes para um Plano de Carreira do SUS; desprecarização do PSF ... tudo isso passa por definições nacionais que podem viabilizar a consolidação do SUS no país. A SBMFC, desde já, é parceira neste mutirão.

Porto Alegre, 21 de junho de 2004. 